CLINICAL STUDY

\title{
Late-night and low-dose dexamethasone-suppressed cortisol in saliva and serum for the diagnosis of cortisol-secreting adrenal adenomas
}

\author{
Timo Deutschbein, Nicole Unger, Jakob Hinrichs ${ }^{1}$, Martin K Walz ${ }^{1}$, Klaus Mann and Stephan Petersenn \\ Department of Endocrinology and Division of Laboratory Research, Medical Center, University of Duisburg-Essen, Hufelandstraße 55, 45122 Essen, \\ Germany and ${ }^{1}$ Department of Surgery and Center of Minimally Invasive Surgery, Kliniken Essen-Mitte, 45136 Essen, Germany \\ (Correspondence should be addressed to S Petersenn; Email: stephan.petersenn@uni-due.de)
}

\begin{abstract}
Objective: In patients with adrenal incidentalomas, hormonally active masses need to be considered, particularly cortisol-producing adenomas (CPA), aldosterone-producing adenomas, and pheochromocytomas. The screening for hypercortisolism relies on confirming excess cortisol secretion and insufficient suppression after dexamethasone. Because of its high correlation with free cortisol and its stress-free collection, salivary cortisol (SaC) may offer advantages over serum cortisol (SeC). We evaluated the value of $\mathrm{SaC}$ and $\mathrm{SeC}$ for the diagnosis of CPA.

Design: Comparative study between 2001 and 2006.

Methods: Thirty-eight patients with confirmed CPA were compared with 18 healthy subjects as well as 48 control patients suffering from aldosterone-producing adenomas $(n=13)$, pheochromocytomas $(n=16)$, or nonfunctioning adenomas $(n=19)$. Sampling of saliva and serum was performed at 2300 and at $0800 \mathrm{~h}$ following low-dose dexamethasone suppression. Receiver operating characteristics analysis was used to calculate thresholds with at least $95 \%$ sensitivity for CPA.

Results: Regarding the cutoffs for late-night cortisol, SaC (4.8 nmol/l, sensitivity $97 \%$, specificity $69 \%$ ) was slightly more specific than $\mathrm{SeC}(115 \mathrm{nmol} / \mathrm{l}$, sensitivity $97 \%$, specificity $63 \%)$. In contrast, the cutoff for dexamethasone-suppressed $\mathrm{SaC}(3.7 \mathrm{nmol} / \mathrm{l}$, sensitivity $97 \%$, specificity $83 \%)$ was slightly less specific than $\mathrm{SeC}(94 \mathrm{nmol} / \mathrm{l}$, sensitivity $97 \%$, specificity $88 \%)$. However, the latter cutoffs demonstrated greater specificity when compared with the cutoffs for late-night cortisol.

Conclusion: The diagnostic accuracy of $\mathrm{SaC}$ is as good as SeC. Owing to its higher specificity, dexamethasone-suppressed cortisol is preferable to late-night cortisol when screening for Cushing's syndrome in patients with adrenal incidentalomas.
\end{abstract}

European Journal of Endocrinology $161747-753$

\section{Introduction}

The overall frequency of incidentally recognized adrenal masses can be as high as $6 \%$, as shown in a report on 19 studies summarizing 86742 autopsies (1). Incidentalomas of the adrenal gland are detected with increased frequency, mainly due to the widespread use as well as the technical improvement of imaging techniques like computed tomography (CT), magnetic resonance imaging, and ultrasonography. For example, unexpected adrenal nodules are encountered in about 5\% of abdominal CT scans performed for whatever reason $(2,3)$. The vast majority of these incidentalomas are either nonfunctioning adrenal adenomas $(2,4,5)$ or adenomas, which are clinically and/or biochemically silent ('subclinical'). With respect to the hormonally active tumors, biochemical evaluation is needed to differentiate between cortisol-producing adenomas (CPA), aldosterone-producing adenomas, and pheochromocytomas. The biochemical screening for CPA relies on confirming hypercortisolism, and three tests are commonly used for diagnostic assessment: measurement of late-night serum or salivary cortisol $(\mathrm{SaC})$, dexamethasone suppression test, and 24-h urinary free cortisol (UFC) $(6,7)$.

Although routinely performed in endocrine practice, both blood and urine sampling are not only stressful, but also labor intensive and time consuming. In contrast, the measurement of $\mathrm{SaC}$ offers several advantages, such as its simple, cost-effective and stress-free collection (8). Thus, late-night $\mathrm{SaC}$ has been frequently used for diagnosing Cushing's syndrome (CS) (9-16). Most studies included few patients with primary adrenal disease, and few data are available for the use of SaC during a dexamethasone suppression test. As a consequence, this prospective study was designed to evaluate the validity of $\mathrm{SaC}$ measurement for the diagnosis of CS in patients with clinically and 
biochemically confirmed CPA. Samples were collected both late at night and at $0800 \mathrm{~h}$ following an overnight low-dose dexamethasone suppression test (LDDST). Thresholds with at least 95\% sensitivity for CS were calculated for each test, using receiver operating characteristics (ROC) curves.

\section{Subjects and methods}

\section{Subjects}

Eighty-six patients with adrenal masses were prospectively enrolled at the time when they were referred for minimally invasive surgery from various endocrine centers in Germany. The 38 CPA patients presented with some clinical signs of CS. Their initial biochemical diagnosis in the primary endocrine center was made with elevated 24-h UFC, insufficient cortisol suppression after dexamethasone, and low ACTH levels (individual results are not provided because UFC reference ranges, criteria for dexamethasone suppressive tests, and laboratory procedures varied among the different primary endocrine centers). The 48 control patients (AdTu) were initially investigated in the primary endocrine center either because of incidentally discovered adrenal masses or clinical findings suggestive of an adrenal tumor (e.g. low potassium concentrations or uncontrolled hypertension). Nineteen of these patients were found to have nonfunctioning adenomas, 16 patients had histologically confirmed pheochromocytomas, and 13 patients with elevated plasma aldosterone concentration to plasma renin activity ratios as well as positive suppression tests, and/or typical clinical symptoms were diagnosed as having aldosteroneproducing adenomas. Of note, careful diagnostic evaluation did not reveal any biochemically and clinically apparent features of subclinical CS coexisting with the underlying disease. All patients were reevaluated before surgical treatment; none of the females were on contraceptives or estrogens, and medications known to affect glucocorticoid metabolism were omitted for at least $24 \mathrm{~h}$ before testing. Moreover, none of the patients had a history of alcohol abuse or psychiatric problems. The control group consisted of 18 healthy subjects. None of these subjects suffered from endocrine disorders or was on medication (including systemic corticosteroids and hormonal contraceptives). The local ethics committee approved the study protocol, and all participants gave their written informed consent.

\section{Collection of samples}

While patients were always tested during a hospital stay, samples from healthy control subjects were taken in an outpatient setting. An indwelling i.v. canulla was inserted into a forearm vein, followed by a recovery period of $15 \mathrm{~min}$ in order to avoid stress-induced cortisol raises. Blood samples for ACTH measurement were obtained at $0800 \mathrm{~h}$ from all patients. Patients as well as healthy controls underwent simultaneous sampling of saliva and serum at $2300 \mathrm{~h}$. Afterwards, $1 \mathrm{mg}$ dexamethasone was administered orally, and matched saliva and serum samples were taken at $0800 \mathrm{~h}$ the next morning. Saliva was collected using the Salivette device (Sarstedt, Germany). If measurement was not performed after testing, samples were stored at $-20^{\circ} \mathrm{C}$.

\section{Measurement of samples}

Plasma ACTH was determined by solid-phase two-site sequential chemiluminescent immunometric assays (Immulite 2000, Siemens, Eschborn, Germany). SaC was assayed using a modification of the 'GammaCoat' RIA (DiaSorin, Stillwater, MN, USA), decreasing the sample volume from 200 to $100 \mu \mathrm{l}$. The lower detection limit of this assay was $0.6 \mathrm{nmol} / \mathrm{l}$, and the intra- and interassay coefficients of variation (CV) were 2.6 and $4.6 \%$ respectively. Serum cortisol $(\mathrm{SeC})$ was measured by a competitive immunoassay (Advia Centaur, Bayer, Fernwald, Germany), with a lower detection limit of $5.5 \mathrm{nmol} / \mathrm{l}$. The intra- and interassay $\mathrm{CV}$ were $<3.8$ and 5.5\% respectively, as determined at various cortisol concentrations (ranging from 107 to $1025 \mathrm{nmol} / \mathrm{l}$ ). The cortisol antiserum of this kit had a $0.2 \%$ cross-reactivity with dexamethasone (as described by the manufacturer). All hormonal measurements were performed in a single laboratory.

\section{Statistical analysis}

Results are expressed as the mean \pm s.E.M. The diagnostic accuracy of each test was investigated using ROC curves, comparing both patient groups (CPA versus AdTu). Kruskal-Wallis tests, followed by Dunn's multiple comparison tests, and Mann-Whitney tests were performed where appropriate. Significance was set at $P<0.05$. Statistical analysis was performed using GraphPad Prism 5.0 software (GraphPad Software Inc., San Diego, CA, USA).

\section{Results}

The clinical characteristics of the three study groups are shown in Table 1. Patients of both groups (CPA and $\mathrm{AdTu}$ ) demonstrated comparable age, body mass index, and tumor size, whereas sex distribution was significantly different $(P<0.05)$. All patients of the CPA group had plasma ACTH levels of $<10 \mathrm{pg} / \mathrm{ml}$.

\section{Cortisol levels at 2300 h}

Mean cortisol was highest in CPA patients, with individual levels ranging from 1.1 to $48.1 \mathrm{nmol} / \mathrm{l} \mathrm{SaC}$ 
Table 1 Clinical characteristics of all study participants. Moreover, mean serum and salivary cortisol levels at 2300 and at $0800 \mathrm{~h}$ respectively are listed. The three study groups are patients with cortisol-producing adenomas (CPA), patients with adrenal masses of different etiology (adrenal tumors), and healthy control subjects (healthy controls). Values are means \pm s.E.M.

\begin{tabular}{llll}
\hline & CPA & $\begin{array}{l}\text { Adrenal } \\
\text { tumors }\end{array}$ & $\begin{array}{l}\text { Healthy } \\
\text { controls }\end{array}$ \\
\hline Subjects $(n)$ & 38 & 48 & 18 \\
Sex & $6 \mathrm{M}, 32 \mathrm{~F}$ & $20 \mathrm{M}, 28 \mathrm{~F}$ & $9 \mathrm{M}, 9 \mathrm{~F}$ \\
Age (years) & $50.2 \pm 2.1$ & $50.4 \pm 2.1$ & $37.1 \pm 1.9$ \\
BMl (kg/m²) & $27.6 \pm 0.8$ & $27.1 \pm 0.7$ & $25.5 \pm 1.1$ \\
Tumor size (cm) & $3.09 \pm 0.13$ & $3.42 \pm 0.36$ & - \\
Salivary cortisol (nmol/l) & & & \\
2300 h & $19.6 \pm 1.9$ & $4.7 \pm 0.4$ & $6.8 \pm 1.2$ \\
$\quad$ 0800 h (after Dex) & $19.7 \pm 1.8$ & $2.8 \pm 0.2$ & $1.8 \pm 0.1$ \\
$\quad \begin{array}{l}\text { Serum cortisol (nmol/l) } \\
\text { 2300 h }\end{array}$ & $441 \pm 31$ & $115 \pm 15$ & $210 \pm 37$ \\
0800 h (after Dex) & $432 \pm 30$ & $44 \pm 5$ & $27 \pm 3$ \\
\hline
\end{tabular}

and from 108 to $845 \mathrm{nmol} / \mathrm{l} \mathrm{SeC}$ respectively (Fig. 1). The AdTu patients tended to have the lowest individual values, although the ranges overlapped those seen in healthy controls $(2.0-16.2$ vs $2.0-18.7 \mathrm{nmol} / \mathrm{l}$ for $\mathrm{SaC}$; $11-556$ vs $42-552 \mathrm{nmol} / \mathrm{l}$ for SeC; Fig. 1). Mean salivary and $\mathrm{SeC}$ levels are listed in Table 1. Highly significant differences were found between the CPA and the AdTu group $(P<0.001$ for salivary as well as $\mathrm{SeC})$, and between the CPA group and the controls $(P<0.001$ for $\mathrm{SaC} ; \mathrm{P}<0.01$ for $\mathrm{SeC}$ ). The $\mathrm{SeC}$ levels found in the AdTu and the control group were slightly different $(P<0.05)$, whereas the $\mathrm{SaC}$ values were comparable (n.s). In general, salivary and $\mathrm{SeC}$ levels were highly correlated $(r=0.77, P<0.0001)$. ROC analysis cutoffs with a high sensitivity for the detection of CS patients of more than $95 \%$ were $4.8 \mathrm{nmol} / \mathrm{l}$ for $\mathrm{SaC}$ (specificity $69 \%$ ) and $115 \mathrm{nmol} / \mathrm{l}$ for SeC (specificity 63\%) respectively (Table 2 ).

\section{Cortisol levels at 0800 h after $1 \mathrm{mg}$ dexamethasone}

Again, mean salivary and $\mathrm{SeC}$ were highest in CPA patients. Individual $\mathrm{SaC}$ levels ranged from 2.7 to $49.3 \mathrm{nmol} / \mathrm{l}$, whereas $\mathrm{SeC}$ ranged from 80 to $845 \mathrm{nmol} / \mathrm{l}$ (Fig. 2). With respect to the AdTu group, salivary and SeC ranges were $0.8-10.0$ and $6-138 \mathrm{nmol} / \mathrm{l}$ respectively, while ranges of $0.9-2.7$ and $13-71 \mathrm{nmol} / \mathrm{l}$ were detected in healthy controls (Fig. 2). All mean levels are summarized in Table 1. Cortisol values in the three study groups differed significantly: CPA versus AdTu, each $P<0.001$ for saliva and serum; CPA versus controls, each $P<0.001$ for saliva and serum. In contrast, the differences between the AdTu and the control group were not statistically significant. Salivary and $\mathrm{SeC}$ levels were again highly correlated $(r=0.81, \quad P<0.0001)$.
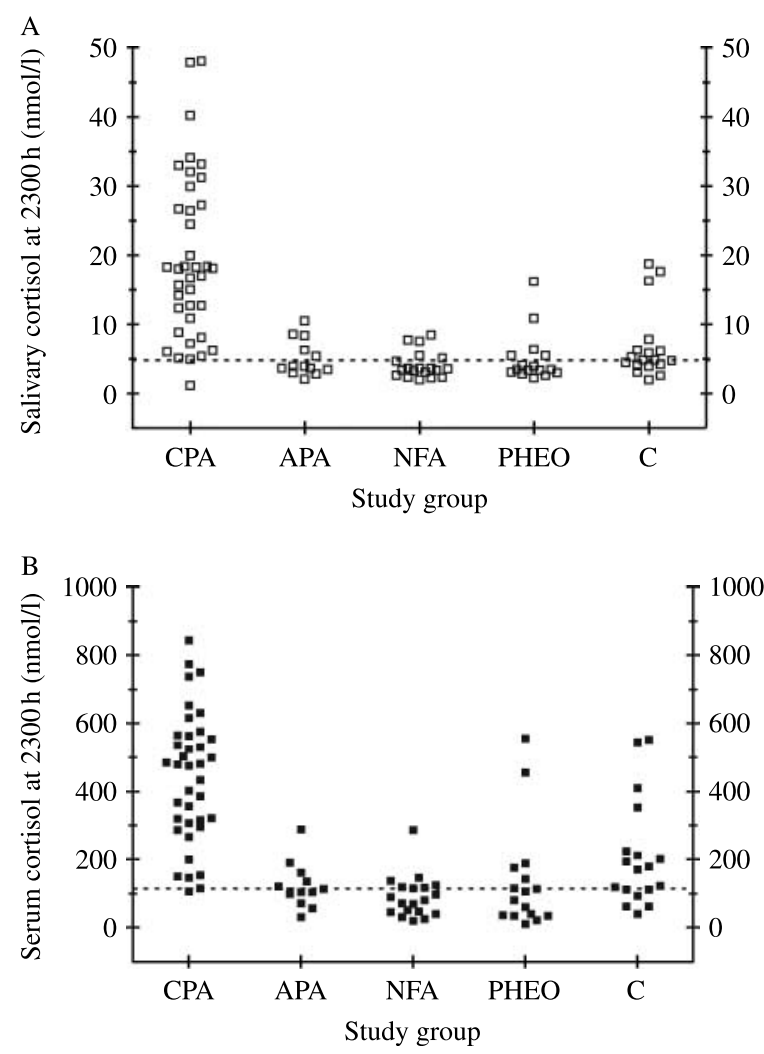

Figure 1 Individual salivary (A) and serum cortisol levels (B) at $2300 \mathrm{~h}$ in patients with adrenal masses and healthy control subjects. The study groups are patients with cortisol-producing adenomas (CPA), patients with aldosterone-producing adenomas (APA), patients with nonfunctioning adenomas (NFA), patients with pheochromocytomas (PHEO), and healthy controls (C).

ROC cutoffs affording high sensitivity ( $>95 \%$ ) for CS were $3.7 \mathrm{nmol} / \mathrm{l}$ for SaC (specificity 83\%) and $94 \mathrm{nmol} / \mathrm{l}$ for SeC (specificity 88\%) (Table 2).

\section{Combination of midnight and dexamethasone- suppressed cortisol}

In addition to the isolated analysis of each of the four single parameters, we also investigated the combined use of midnight and dexamethasone-suppressed cortisol, applying the thresholds that had been identified before. The combined analyses of either serum or saliva were found to have slightly higher sensitivity (both $100 \%$ ), but lower specificity (serum 56\%, saliva 65\%) than the single parameters.

\section{Discussion}

Several procedures are recommended for the initial screening for hypercortisolism, such as repeated 24-h UFC determination, low-dose dexamethasone suppression, and measurement of late-night cortisol $(6,7)$. 
Table 2 Receiver operating characteristics analysis for serum and salivary cortisol levels at 2300 and at $0800 \mathrm{~h}$ respectively. Each threshold is listed with its corresponding sensitivity, specificity, area under the curve (AUC), and significance. Cutoffs were calculated by comparing patients with cortisol-producing adenomas and with adrenal masses of other etiologies.

\begin{tabular}{lccccc}
\hline & Cutoff $(\mathrm{nmol} / \mathrm{l})$ & Sensitivity $(\%)$ & Specificity $(\%)$ & AUC & Significance $(P)$ \\
\hline 2300 h Serum & 115 & 97 & 63 & 0.94 & $<0.0001$ \\
0800 Serum (after Dex) & 94 & 97 & 88 & 0.99 & $<0.0001$ \\
2300 h Saliva & 4.8 & 97 & 69 & 0.93 & $<0.0001$ \\
0800 h Saliva (after Dex) & 3.7 & 97 & 83 & 0.97 & $<0.0001$ \\
\hline
\end{tabular}

The finding of increased UFC levels and decreased ACTH concentrations is usually sufficient to establish the diagnosis of hypercortisolism in patients with clinical signs of CS referred for an adrenal tumor. However, adequate urine collection is difficult, especially in children and the elderly. Moreover, it may require several collections to rule out intermittent cortisol excess, which may be inconvenient for patients. Finally, measurement of UFC by immunoassay is often influenced by cross-reactivity with cortisol metabolites or exogenous glucocorticoids, and normal ranges are not very well established for some of the newer immunoassays. Consequently, ACTH measurements combined with late-night and/or dexamethasonesuppressed cortisol levels are potential alternatives when screening for CS.

Our late-night $\mathrm{SeC}$ cutoff of $115 \mathrm{nmol} / \mathrm{l}$ falls within the range provided by previous studies. While some authors showed that thresholds between 207 (17) and $229 \mathrm{nmol} / \mathrm{l}$ (18) had both high sensitivity and specificity, Newell-Price et al. (19) suggested a single midnight sleeping $\mathrm{SeC}$ cutoff of $50 \mathrm{nmol} / \mathrm{l}$. This test, however, required inpatient admission for at least $48 \mathrm{~h}$ to avoid false-positive results due to the stress of hospitalization, and blood had to be drawn within the first minutes of waking the patient. Our observations are comparable with findings by Görges et al. (20) who found a sensitivity of $100 \%$ and a specificity of $77 \%$ for a cutoff of $140 \mathrm{nmol} / \mathrm{l}$. Of note, we observed some unusually high cortisol levels at $2300 \mathrm{~h}$ in both the AdTu and the control group. This may point to potential influences of stress, which are more likely to occur in random samples than in samples collected during dynamic suppression tests (with defined sampling conditions).

In comparison with blood and urine sampling, the noninvasive collection of saliva is stress-free and much easier to perform in an outpatient setting (8). SaC is not influenced by cortisol-binding globulin levels, which are often altered by severe diseases or certain drugs (21-23). Therefore, $\mathrm{SaC}$ represents an excellent index of the free and biologically active rather than the proteinbound hormone (24). Its concentrations are independent of salivary flow, storage conditions, dental care, and food respectively (25-28). Furthermore, it has been shown that the impact of blood leakage due to microinjury on the oral mucosa is negligible (29). In this context, late-night $\mathrm{SaC}$ measurement has been repeatedly described as a convenient and reliable screening test for CS $(10,12-16)$. These studies reported sensitivities and specificities from 92 to $100 \%$ and from 93 to $100 \%$ respectively with thresholds varying from 3.6 to $15.2 \mathrm{nmol} / \mathrm{l}$. Besides, a recent publication by Nunes et al. (30) demonstrated that late-night $\mathrm{SaC}$ is of great diagnostic value when screening for CS. This was true regardless of whether patients were investigated on an inpatient or an outpatient basis. However, most papers published to date included only small groups with CPA. With respect to our prospective evaluation, a cutoff of $4.8 \mathrm{nmol} / \mathrm{l} \mathrm{had}$ similar sensitivity, but lower specificity in patients with adrenal masses.
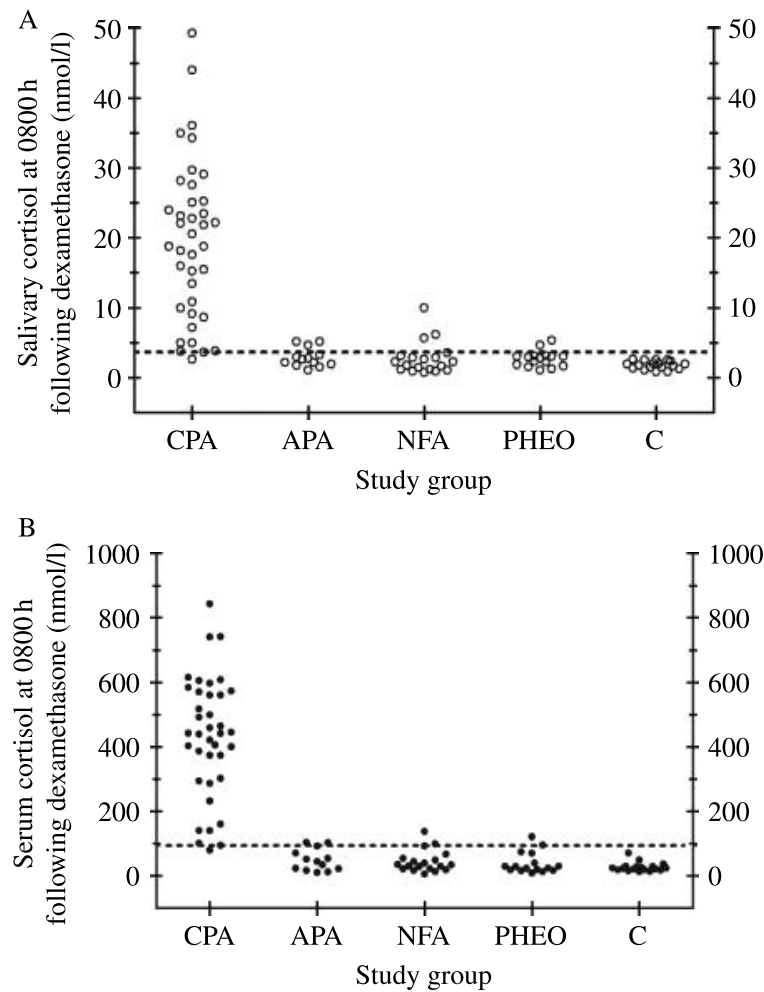

Figure 2 Individual salivary (A) and serum cortisol levels (B) at $0800 \mathrm{~h}$ (after $1 \mathrm{mg}$ dexamethasone) in patients with adrenal masses and healthy control subjects. The study groups are patients with cortisol-producing adenomas (CPA), patients with aldosteroneproducing adenomas (APA), patients with nonfunctioning adenomas (NFA), patients with pheochromocytomas (PHEO), and healthy controls $(C)$. 
Several studies found dexamethasone tests to be the most appropriate screening tools for CS due to CPA $(2,5,31-34)$. Various doses have been used, but most groups preferred the LDDST with $1 \mathrm{mg}$ dexamethasone, which has also been recommended by the National Institutes of Health Consensus Development Program (35). The optimal threshold is still debated, but reported cutoffs for SeC suppression usually range from 100 to $200 \mathrm{nmol} / \mathrm{l}(36-38)$. More recently, some experts suggested lower SeC cutoffs for the LDDST, mainly with the intention to raise sensitivity $(6,7,38-40)$. In our prospective analysis of patients with adrenal masses, however, a threshold of $50 \mathrm{nmol} / \mathrm{l}$ was found to have only slightly higher sensitivity, but resulted in profound loss of specificity.

In contrast to late-night $\mathrm{SaC}$, less is known about $\mathrm{SaC}$ determination after low-dose dexamethasone suppression. Up to now, only few groups investigated the validity of this method, providing cutoffs between 1.5 and $2.8 \mathrm{nmol} / \mathrm{l}(11,16,41,42)$. Of note, these studies have mainly focused on patients with Cushing's disease, while only few subjects with CPA were included. To the best of our knowledge, this is the first study in which cutoffs were calculated by comparison with a group of patients with adrenal masses of other etiologies. In contrast, comparison with healthy controls may give misleading results, especially since screening for hypercortisolism is usually initiated when clinical suspicion is high. In our study, the diagnostic performance of the LDDST was somewhat superior to late-night cortisol measurement, mainly because of its higher specificity. Although SeC showed slightly better accuracy, the difference to $\mathrm{SaC}$ was negligible. The combination of midnight and dexamethasone-suppressed cortisol in either serum or saliva yield improved sensitivity to $100 \%$, whereas specificity decreased. As a consequence, we regard the determination of SaC during the LDDST as first-line test for evaluating patients with adrenal incidentalomas. Performed in an outpatient setting, this test is a simple, convenient, and economical screening tool.

It is important to keep in mind that there are also some disadvantages to the LDDST. For instance, Crapo et al. (43) reported that the rate of false-positive results is considerably higher in the presence of obesity, psychiatric disorders, chronic illness, and certain drugs respectively. In these cases, further confirmatory testing may be required. Besides, although we did not observe this phenomenon in our recent study, some CS patients retain cortisol suppression to dexamethasone (20, 40, 44). This unusual sensitivity may be due to individual differences in the absorption and metabolism of dexamethasone. For instance, patients with liver and/or adrenal failure may suffer from impaired glucocorticoid clearance, whereas drugs as well as alcohol may induce its hepatic metabolism (7). Some experts suggested simultaneous measurement of dexamethasone levels in order to minimize the number of false-positive or false-negative tests, but this approach may not be feasible because of the limited availability and the relatively high costs of dexamethasone assays. Consequently, if clinical suspicion of CS remains high, other diagnostic procedures may be more helpful.

It also has to be kept in mind that patients with only mild or even subclinical CS are difficult to detect, since it was noted that none of the common testing procedures achieved sensitivity $>80 \%$ (4). Therefore, the gold standard for establishing the diagnosis of milder forms of CS remains uncertain and is a subject of ongoing debate $(5,45)$. It is unclear whether an early diagnosis made on low cutoffs is helpful, considering that further diagnostic evaluation is needed in a large number of subjects with false-positive screening results. Apart from that, even if diagnosis is confirmed, its adequate therapy may still be uncertain. In this context, follow-up studies that address the outcome after adrenalectomy in comparison with the preoperative biochemical presentation would be of great interest.

With respect to the large variability of cutoffs provided for $\mathrm{SaC}$, the choice of assay should be considered carefully. When testing the same saliva samples in two different assays, both Raff et al. (46) and Papanicolaou et al. (12) observed a wide variability in the absolute cortisol concentrations. Accordingly, determination of $\mathrm{SaC}$ requires careful evaluation of the specific procedure applied. This is especially true since its concentrations are at far lower levels than in serum, being close to the functional limit of detection of most assays.

In conclusion, the diagnostic accuracy of $\mathrm{SaC}$ is at least as good as SeC. This was true regardless of whether samples were collected at $2300 \mathrm{~h}$ or at $0800 \mathrm{~h}$ after $1 \mathrm{mg}$ dexamethasone. However, owing to its higher specificity, dexamethasone-suppressed cortisol may be preferred to late-night cortisol. In comparison with their diagnostic accuracies in Cushing's disease, both tests have lower specificity for differentiating cortisol-secreting adenomas from other adrenal tumors, emphasizing the need for additional tests to confirm the diagnosis.

\section{Declaration of interest}

The authors declare that there is no conflict of interest that could be perceived as prejudicing the impartiality of the research reported.

\section{Funding}

This research did not receive any specific grant from any funding agency in the public, commercial, or not-for-profit sector.

\section{Acknowledgements}

We wish to thank Bianca Ueberberg, Ina Binse, and Ricarda Althoff for their support of this work. 


\section{References}

1 Kloos RT, Gross MD, Francis IR, Korobkin M \& Shapiro B. Incidentally discovered adrenal masses. Endocrine Reviews 1995 16 460-484.

2 Young WF Jr. Management approaches to adrenal incidentalomas. A view from Rochester, Minnesota. Endocrinology and Metabolism Clinics of North America 200029 159-185.

3 Song JH, Chaudhry FS \& Mayo-Smith WW. The incidental adrenal mass on CT: prevalence of adrenal disease in 1,049 consecutive adrenal masses in patients with no known malignancy. American Journal of Roentgenology 2008190 1163-1168.

4 Mantero F, Terzolo M, Arnaldi G, Osella G, Masini AM, Ali A, Giovagnetti M, Opocher G \& Angeli A. A survey on adrenal incidentaloma in Italy. Study Group on Adrenal Tumors of the Italian Society of Endocrinology. Journal of Clinical Endocrinology and Metabolism 200085 637-644.

5 Mansmann G, Lau J, Balk E, Rothberg M, Miyachi Y \& Bornstein SR. The clinically inapparent adrenal mass: update in diagnosis and management. Endocrine Reviews 200425 309-340.

6 Newell-Price J, Bertagna X, Grossman AB \& Nieman LK. Cushing's syndrome. Lancet 2006367 1605-1617.

7 Nieman LK, Biller BM, Findling JW, Newell-Price J, Savage MO, Stewart PM \& Montori VM. The diagnosis of Cushing's syndrome: an endocrine society clinical practice guideline. Journal of Clinical Endocrinology and Metabolism 200893 1526-1540.

8 Lewis JG. Steroid analysis in saliva: an overview. Clinical Biochemist. Reviews 200627 139-146.

9 Luthold WW, Marcondes JA \& Wajchenberg BL. Salivary cortisol for the evaluation of Cushing's syndrome. Clinica Chimica Acta $198515133-39$.

10 Raff H, Raff JL \& Findling JW. Late-night salivary cortisol as a screening test for Cushing's syndrome. Journal of Clinical Endocrinology and Metabolism $1998 \mathbf{8 3} 2681-2686$.

11 Castro M, Elias PC, Quidute AR, Halah FP \& Moreira AC. Outpatient screening for Cushing's syndrome: the sensitivity of the combination of circadian rhythm and overnight dexamethasone suppression salivary cortisol tests. Journal of Clinical Endocrinology and Metabolism $1999 \mathbf{8 4} 878-882$.

12 Papanicolaou DA, Mullen N, Kyrou I \& Nieman LK. Nighttime salivary cortisol: a useful test for the diagnosis of Cushing's syndrome. Journal of Clinical Endocrinology and Metabolism 2002 87 4515-4521.

13 Putignano P, Toja P, Dubini A, Pecori Giraldi F, Corsello SM \& Cavagnini F. Midnight salivary cortisol versus urinary free and midnight serum cortisol as screening tests for Cushing's syndrome. Journal of Clinical Endocrinology and Metabolism 2003 88 4153-4157.

14 Yaneva M, Mosnier-Pudar H, Dugue MA, Grabar S, Fulla Y \& Bertagna X. Midnight salivary cortisol for the initial diagnosis of Cushing's syndrome of various causes. Journal of Clinical Endocrinology and Metabolism 200489 3345-3351.

15 Trilck M, Flitsch J, Ludecke DK, Jung R \& Petersenn S. Salivary cortisol measurement - a reliable method for the diagnosis of Cushing's syndrome. Experimental and Clinical Endocrinology $\mathcal{E}$ Diabetes $2005113225-230$.

16 Viardot A, Huber P, Puder JJ, Zulewski H, Keller U \& Muller B. Reproducibility of nighttime salivary cortisol and its use in the diagnosis of hypercortisolism compared with urinary free cortisol and overnight dexamethasone suppression test. Journal of Clinical Endocrinology and Metabolism 200590 5730-5736.

17 Papanicolaou DA, Yanovski JA, Cutler GB Jr, Chrousos GP \& Nieman LK. A single midnight serum cortisol measurement distinguishes Cushing's syndrome from pseudo-Cushing states. Journal of Clinical Endocrinology and Metabolism $1998 \mathbf{8 3}$ 1163-1167.

18 Reimondo G, Allasino B, Bovio S, Paccotti P, Angeli A \& Terzolo M. Evaluation of the effectiveness of midnight serum cortisol in the diagnostic procedures for Cushing's syndrome. European Journal of Endocrinology 2005153 803-809.
19 Newell-Price J, Trainer P, Perry L, Wass J, Grossman A \& Besser M. A single sleeping midnight cortisol has $100 \%$ sensitivity for the diagnosis of Cushing's syndrome. Clinical Endocrinology 199543 545-550.

20 Gorges R, Knappe G, Gerl H, Ventz M \& Stahl F. Diagnosis of Cushing's syndrome: re-evaluation of midnight plasma cortisol vs urinary free cortisol and low-dose dexamethasone suppression test in a large patient group. Journal of Endocrinological Investigation 199922 241-249.

21 Meulenberg PM, Ross HA, Swinkels LM \& Benraad TJ. The effect of oral contraceptives on plasma-free and salivary cortisol and cortisone. Clinica Chimica Acta 1987165 379-385.

22 Hamrahian AH, Oseni TS \& Arafah BM. Measurements of serum free cortisol in critically ill patients. New England Journal of Medicine 2004350 1629-1638.

23 Klose M, Lange M, Rasmussen AK, Skakkebaek NE, Hilsted L, Haug E, Andersen M \& Feldt-Rasmussen U. Factors influencing the adrenocorticotropin test: role of contemporary cortisol assays, body composition, and oral contraceptive agents. Journal of Clinical Endocrinology and Metabolism 200792 1326-1333.

24 Umeda T, Hiramatsu R, Iwaoka T, Shimada T, Miura F \& Sato T. Use of saliva for monitoring unbound free cortisol levels in serum. Clinica Chimica Acta $1981110245-253$.

25 Vining RF, McGinley RA \& Symons RG. Hormones in saliva: mode of entry and consequent implications for clinical interpretation. Clinical Chemistry 198329 1752-1756.

26 Chen YM, Cintron NM \& Whitson PA. Long-term storage of salivary cortisol samples at room temperature. Clinical Chemistry 199238304.

27 Clements AD \& Parker CR. The relationship between salivary cortisol concentrations in frozen versus mailed samples. Psychoneuroendocrinology 199823 613-616.

28 Groschl M, Wagner R, Rauh M \& Dorr HG. Stability of salivary steroids: the influences of storage, food and dental care. Steroids 200166 737-741.

29 Kivlighan KT, Granger DA, Schwartz EB, Nelson V, Curran M \& Shirtcliff EA. Quantifying blood leakage into the oral mucosa and its effects on the measurement of cortisol, dehydroepiandrosterone, and testosterone in saliva. Hormones and Behavior $2004 \mathbf{4 6}$ 39-46

30 Nunes ML, Vattaut S, Corcuff JB, Rault A, Loiseau H, Gatta B, Valli N, Letenneur L \& Tabarin A. Late-night salivary cortisol for diagnosis of overt and subclinical Cushing's syndrome in hospitalized and ambulatory patients. Journal of Clinical Endocrinology and Metabolism 200979 1532-1539.

31 Huiras CM, Pehling GB \& Caplan RH. Adrenal insufficiency after operative removal of apparently nonfunctioning adrenal adenomas. Journal of the American Medical Association 1989261 894-898.

32 Osella G, Terzolo M, Borretta G, Magro G, Ali A, Piovesan A, Paccotti P \& Angeli A. Endocrine evaluation of incidentally discovered adrenal masses (incidentalomas). Journal of Clinical Endocrinology and Metabolism 199479 1532-1539.

33 Tsagarakis S, Roboti C, Kokkoris P, Vasiliou V, Alevizaki C \& Thalassinos N. Elevated post-dexamethasone suppression cortisol concentrations correlate with hormonal alterations of the hypothalamo-pituitary adrenal axis in patients with adrenal incidentalomas. Clinical Endocrinology 199849 165-171.

34 Emral R, Uysal AR, Asik M, Gullu S, Corapcioglu D, Tonyukuk V \& Erdogan G. Prevalence of subclinical Cushing's syndrome in 70 patients with adrenal incidentaloma: clinical, biochemical and surgical outcomes. Endocrine Journal 200350 399-408.

35 Grumbach MM, Biller BM, Braunstein GD, Campbell KK, Carney JA, Godley PA, Harris EL, Lee JK, Oertel YC, Posner MC, Schlechte JA \& Wieand HS. Management of the clinically inapparent adrenal mass ("incidentaloma"). Annals of Internal Medicine 2003138 424-429.

36 Cronin C, Igoe D, Duffy MJ, Cunningham SK \& McKenna TJ. The overnight dexamethasone test is a worthwhile screening procedure. Clinical Endocrinology 199033 27-33. 
37 Montwill J, Igoe D \& McKenna TJ. The overnight dexamethasone test is the procedure of choice in screening for Cushing's syndrome. Steroids 199459 296-298.

38 Wood PJ, Barth JH, Freedman DB, Perry L \& Sheridan B. Evidence for the low dose dexamethasone suppression test to screen for Cushing's syndrome - recommendations for a protocol for biochemistry laboratories. Annals of Clinical Biochemistry 1997 $34222-229$.

39 Valli N, Catargi B, Ronci N, Vergnot V, Leccia F, Ferriere JM, Chene G, Grenier N, Laurent F \& Tabarin A. Biochemical screening for subclinical cortisol-secreting adenomas amongst adrenal incidentalomas. European Journal of Endocrinology $2001 \mathbf{1 4 4}$ 401-408.

40 Isidori AM, Kaltsas GA, Mohammed S, Morris DG, Jenkins P, Chew SL, Monson JP, Besser GM \& Grossman AB. Discriminatory value of the low-dose dexamethasone suppression test in establishing the diagnosis and differential diagnosis of Cushing's syndrome. Journal of Clinical Endocrinology and Metabolism 2003 88 5299-5306.

41 Barrou Z, Guiban D, Maroufi A, Fournier C, Dugue MA, Luton JP \& Thomopoulos P. Overnight dexamethasone suppression test: comparison of plasma and salivary cortisol measurement for the screening of Cushing's syndrome. European Journal of Endocrinology 1996134 93-96.

42 Cardoso EM, Arregger AL, Tumilasci OR \& Contreras LN. Diagnostic value of salivary cortisol in Cushing's syndrome (CS). Clinical Endocrinology 2009 70 516-521.

43 Crapo L. Cushing's syndrome: a review of diagnostic tests. Metabolism $1979 \mathbf{2 8} 955-977$.

44 Findling JW, Raff H \& Aron DC. The low-dose dexamethasone suppression test: a reevaluation in patients with Cushing's syndrome. Journal of Clinical Endocrinology and Metabolism 2004 89 1222-1226.

45 Terzolo M, Reimondo G, Bovio S \& Angeli A. Subclinical Cushing's syndrome. Pituitary 20047 217-223.

46 Raff H, Homar PJ \& Burns EA. Comparison of two methods for measuring salivary cortisol. Clinical Chemistry 200248 207-208.

Received 4 August 2009

Accepted 11 August 2009 